\title{
NóTUlA SOBRE O CONTRIBUTO DE DELFIM SANTOS À EPISTEMOLOGIA PSICOLÓGICA
}

\section{Por Joaquim Bairrão}

Em outro escrito $\left(^{1}\right)$ tentámos frisar a importância dum estudo dos fundamentos da própria ciência, neste caso a Psicologia, como proémio ao problema do método.

Reparámos que a maior parte dos autores que entre outros se ocuparam recentemente deste tema: FRAISSE, REUCHLIN, e anteriormente ANDREWS, apenas referiram tais problemas, e que só em PIAGET encontrámos uma análise epistemológica do problema do método. Este último autor mostra-o claramente na monumental obra que dirige «Études d'Épistémologie Génétique», noutros escritos mais recentes, como «Sagesse et Illusions de la Philosophie», e ainda numa alocução ao Congresso de Psicologia de Moscovo de 1966.

No nosso já referido artigo salientámos a importância das seguintes noções, no estudo que nos propuséramos, a saber: linguagem, níveis do real, unidade da ciência, «leitura do real», linguagem e meta-linguagem. Igualmente analisámos alguns aspectos das obras de $\mathrm{KOCH}$, FRAISSE, RA-

() BAIRRÃO. J. 一《Alguns aspectos do Método em Psicologia Infantil». I) Introdução ao Problema do Método em Psicologia. a) Linguagem e Meta-Linguagem.

b) Considerações epistemológicas (a publicar pròximamente) 
PAPORT, GUILLAUME e BACHELARD, tendo sobretudo sublinhado a dificuldade duma linguagem única em Psicologia, e consequentemente o carácter necessitativo de metodologias concorrentes.

A referida problemática, que hoje volta a tomar importante aspecto na Psicologia e na Filosofia das Ciências, está patente, embora em graus e intenções diferentes, em autores como PIAGET, GRECO ou RAPAPORT, e parece-nos de importância decisiva para o cientista quando este pretende saber sobre que zona do real actua. Igualmente na articulação dos vários níveis de realidade, e finalmente na delimitação da Teoria e da Prática, neste caso da Psicologia tão importante, porquanto é sobre o Homem e para o Homem que uma e outra se exercem ou se destinam.

Ainda no referido artigo, embora muito ràpidamente, atentámos na noção de paralelismo, ou paralelismos, (esquema fácil, mas de difícil crítica), e na de reducionismos, i.e., na tentativa de redução da Psicologia ao modelo das outras ciências: - o fascínio ou ideal da Matemática, o de objectividade da Física, ou o funcional da Biologia.

Finalmente recordámos as novas orientações de «convergênoia», e as eventuais pontes interdisciplinares-PRIBRAM, MILLER (M. H.), HECAEN, etc. $\left({ }^{2}\right)$.

Mas, qual a razão de vos falar tão demoradamente do que fizemos? Por duas razỗes: em primeiro lugar, para vos situar no contexto do nosso referido artigo, e em segundo lugar, para vos poder falar daquele que hoje recordamos e que em vida mostrara por esse nosso trabalho uma generosa atenção.

Na realidade, a obra de Delfim Santö, que está longe de ser estudada, é, no pouco que conhecemos, de inestimável valia para os problemas de

() PRIBRAM, K. M. - «Interrelations of Psychology and the Neurological Disciplines», in KOCH (S.) - «Psychology - A Study of a Science», vol. 4, Study II, McGraw-Hill.

HECAEN, H.—《La Neuropsychologie, son objet, ses méthodes», Journal Psych. Norm. Pathol., n. ${ }^{\circ}$ 2, Avril-Juin 1966.

MILLER, M. H. - «On Building Bridges», in «Psychoanalysis and Current Biological Thought», Ed. Greenfield and Lewys, The University of Wisconsin Press, 1965.
Psicologia, não só pelas notáveis aptidões do autor, mas também por ser de língua portuguesa e apresentar críticas e exposições de sistemas de difícil acesso.

Pensamos sobretudo nas obras: «Situação Valorativa do Positivismo» (Berlim 1938) e «Conhecimento e Realidade» (Lisboa 1940), onde, embora não se referindo especialmente à Psicologia, Delfim Santos visa a fundamentação da Ciência ao tratar do problema do Conhecimento.

Tal preocupação está patente em GRECO e PIAGET, embora nestes últimos a intenção seja ao mesmo tempo psicológica e epistemológica, PIAGET é levado à análise do seu contributo para uma Filosofia válida. O seu itinerário é duma Psicologia à Epistemologia e desta última, de novo, à Psicologia.

Ora uma tal preocupação não surge assim tão delineada na obra do autor da «Fundamentação Existencial da Pedagogia», mas as suas reflexões são importantes para a primeira parte dum itinerário filosófico dessa natureza. Não foi por acaso que citámos a «Fundamentação...» (Lisboa 1946), embora não seja aqui o lugar nem a ocasião para traçar as relações epistemológicas entre as obras citadas de Delfim Santos e esta última.

$\mathrm{Na}$ «Situação Valorativa.... estuda-se com admirável precisão e clareza a importância das noções de língua e linguagem e mostra-se a evolução das linguagens, que poderão fundamentar os reducionismos, problema crucial em Psicologia. Diz-se na pág. 4: «...ou admitimos uma língua única, rigorosamente adequada, que deverá ser um absoluto de referência para todos os aspectos da realidade; ou admitimos que estes diferentes aspectos da realidade são na verdade diferentes e que qualquer tradução numa língua unitária (sublinhado nosso), daria deles apenas o que eles têm de semelhante interpretado como idêntico» $\left({ }^{3}\right)$.

Tal afirmação encontra eco nos já referidos autores e nas preocupações dos psicólogos das mais variadas tendências: KOCH, RAPAPORT, e nos escritos dos neo-behavioristas ou dos psicanalistas neo-positivistas, etc.

A razão ou razões de tal atitude são muitas, mas salientam sobretudo uma «crise» donde a ciência sairá mais fortalecida e original. A «crise» é

() SANTOS, Delfim - «Situação Valorativa do Positivismo», pág. 5. A leitura da pág. 4 é indispensável à compreensão deste passo, sobretudo quando o autor fala de língua e sub-línguas e linguagem. 
também sensível em «Conhecimento e Realidade», e resume-se na falsa posição de se julgar ter encontrado em Ciência o rumo imutável duma linguagem. Recordamos que o problema da linguagem em Psicologia está patente na sua história, de FECHNER aos nossos dias, e embora não seja predominantemente «dual» pode incluir-se no esquema de que Delfim Santos fala ainda a propósito de linguagem ( $\left.{ }^{4}\right)$ : «...no primeiro caso, se 0 sistema de referência fosse a linguagem da Física, teríamos o fisicalismo como língua universal. ....No segundo caso, seríamos obrigados a admitir tantas linguagens especiais quantos fossem os aspectos da realidade a considerar especial e separadamente, cada uma destas sub-línguas seria tanto mais perfeita quanto mais difícil fosse a tradução duma em qualquer das outras. De certo modo, e em parte foi este o caminho seguido para cada ciência, primeiro pela particularização da realidade em regiões e, depois pela criação duma aparelhagem conceptual e simbólica em princípio intrasponível....».

Seria interessante comparar este passo com a análise da posição de PIAGET quando nos fala da genética da noção de conceito e símbolo, embora tal desígnio nos pareça nesta ocasião extemporâneo.

Igualmente em «Conhecimento e Realidade» encontraríamos de novo essa preocupação, de tão grande actualidade que não podemos deixar de a assinalar.

Não nos alongamos nesta «apressada» nota, pois o que já dissemos é um ponto de partida e um convite ao exame atento da obra de Delfim Santos.

O mesmo poderíamos aduzir para outras noções que o autor igualmente tratou de modo inconfundível. A noção de causalidade é uma dessas, que encontra eco em autores de tão diversa orientação como RENÉ. ZAZZO.

Em conferência actual, «Introduction aux thèmes de recherches sur le contrôle», ZAZZO recorda a noção de causalidade na análise e separação de diferentes níveis de realidade. Acerca do fisiológico e do psicológico, onde tal noção é susceptível de induzir em erro, sobretudo na sua formação clássica. Propõe então a par duma causalidade linear outra mais vasta, que permita quebrar essa linearidade não mais comportável com os progressos da Psicologia.

\footnotetext{
(') «Situação Valorativa do Positivismo», pág. 5: e segs.
}

E Delfim Santos ainda quem nos diz: «...Todavia o princípio da causalidade é um sério problema para a Epistemologia contemporânea. A noção tradicional de causa perdeu o sentido que possuía e foram descobertos outros tipos de dependência entre fenómenos, diferentes da dependência causal. $\bigcirc$ conceito de relação, como já mostrámos, não é unívoco e igualmente o não é o conceito de dependência e o conceito de função, com os quais a causalidade foi identificada». («Sit. Valor. Posit.», pág. 112).

Embora Delfim Santos tenha em vista a crítica do Positivismo e se sirva na sua argumentação de exemplos tirados da Física, a sugestão para o psicólogo aí fica, se nos recordarmos das etapas históricas que esta ciência percorreu e da sua necessidade de recorrer a outros esquemas explicativos por caducos os antigos, como ZAZZO acentua, com que a Filosofia tradicional pensara resolver os problemas psicológicos.

Não será a altura em Psicologia de se recorrer a um outro tipo de causalidade? Não será que as explicações nesta ciência eram ainda precoces a todos os níveis, e confundidas muitas vezes çom a descrição ou leitura dos fenómenos, por atraso de metodologias adequadas?

Por agora contentamo-nos em aflorar estes problemas quase do senso comum por tão debatidos nos últimos decénios.

Recordamos o que em outro lugar dissemos a propósito da Psicanálise: «...A Psicologia tem de operar uma tríplice síntese para criar a sua própria meta-linguagem...». Hoje, e depois da advertência de Delfim Santos, talvez disséssemos mais cautelosamente que a síntese será caracterizada principalmente pela criação duma linguagem, para só depois se cuidar da sua fundamentação.

Paris, 19 de Novembro de 1966. 


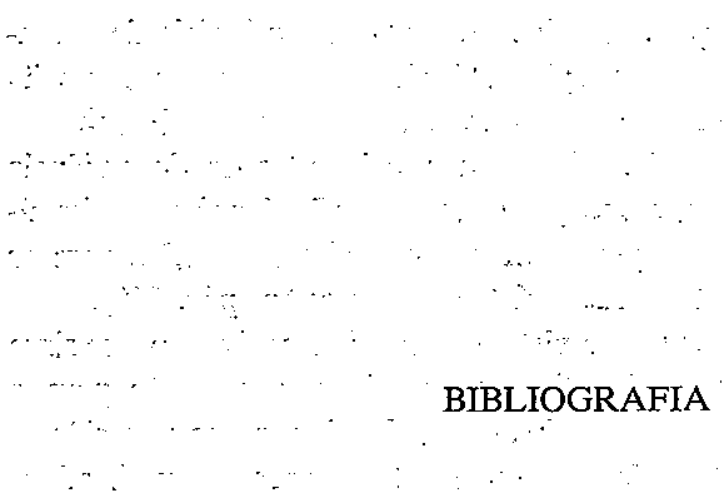

SANTOS, D. - «Situação Valorativa do Positivismo». Berlim, 1938; «Conhecimento e Realidade», Lisboa, 1940.

FRAISSE, P. - «Manuel Pratique de Psychologie Expérimentale», P. U. F., 1956; ver Avant-Propos: «Défense de la Méthode Expérimentale en Psychologie».

FRAISSE e PIAGET - «Traité de Psychologie Expérimentale», Tome I; chaps. I II, III, IV, (respectivamente de Fraisse, Fraisse, Piaget, Reuchlin), P. U. F., 1963.

PIÁGET:- «Traité de Psychologie Expérimentale», Tome VII: chaps XXIV (Piaget e Inhelder), e XXV (Gréco, P.); P. U. F., 1963; «Sagesse et Illusions de la Philosophie», P. U. F., 1965.

REUCHCIN, M.) - «Les Méthodes Quantitatives en Psychologie» (Introduction) P. U. F., 1962

GUILLAUME, P. --)《Introduction à la Psychologie», Vrin, 1964.

KOCH, S. - «Psychology. A Study of a Science». (Introdução), Vol. I, Study I, Mc Graw-Hill.

RAPAPORT - In Koch: «Psych. St. Sc.», vol. 2, Study IV - The Structure of Psychoanalytical System», Mc Graw-Hill.

PRIBRAM - In Koch: «Psych. St. Sc.», vol. 4, Study II - Interrelations of Psychology and the Neurological Disciplines, Mc Graw-Hill.

HECAEN, H. - «La Neuropsychologie son object ses méthodes», Journal Psych. N. Path. 2, 1966.

ZAZZO, R. - Conferência não publicada.

\section{DELFIM SANTOS, O PEDAGOGISTA $\mathrm{E}$ O PEDAGOGO}

\section{Por Rui Grácio}

Seṇhor Presidente da Fựdação Calouste Gulbenkian,

Senhor Reitor,

Senhor Presidente da Sociedade Portuguesa de Psicologia,

Minhas Senhoras, meus Senhores.

Não obstante nos encontrarmos aqui concitados por uma sociedade científica, não podemos iludir o facto de que este encontro não visa tanto o estudo da obra de Delfim Santos como tributar a homenagem merecida por quem, deixando-nos de algum modo para sempre, deixou mais pobre e mais limitada nos seus horizontes a vida cultural portuguesa.

Estudar a obra de alguém é já de certo venerar quem a criou, mas hoje, aqui, a tónica dominante incíde na homenagem. Com efèito, muito embora o nome de Delfim Santos tenha sido pùblicamente evocado, aqui e. ali, nos últimos dois a três meses, esta é a primeira sessão exclusivamente dedicada a lembrá-lo, e honras são devidas por isso à Sociedade Portuguesa de Psicologia de cuja Assembleia Geral o Prof. Delfim Santos foi presidente. Outra razão faz prevalecer a homenagem sobre o estudo: a profusão de dispersos e inéditos obriga a acautelar o juízo do estudioso. Estamos aliás aqui menos para juIgar do que para ensaiar compreender, e isto me permite transitar para uma terceira razão, esta estritamente pessoal, e que é uma razão do coração: a presença de Delfim Santos está demasiado próxima para eu tentar situar valorativamente, com a objectividade possível nas coisas humanas, o pensamento do pedagogista e a acção. do pedagogo. 